ISSN: 1641-4713; e-ISSN: 2081-1160

DOI: https://doi.org/10.36551/2081-1160.2021.28.311-334

\title{
Percepción de los estudiantes suramericanos hacia ciudadanos extranjeros: Un estudio vinculante sobre inmigración y xenofobia
}

\author{
Perception of South American students towards foreign citizens: \\ A binding study on immigration and xenophobia
}

\author{
Chess Emmanuel Briceño Núñez \\ Universidad Nacional Abierta de Venezuela, Venezuela \\ ORCID iD: https://orcid.org/0000-0002-1712-4136 \\ E-mail: chesspiare@gmail.com
}

Recepción: 9.04.2021

Aprobación: 20.09.2021

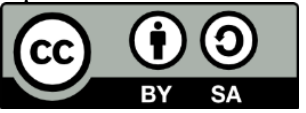

Resumen: Este documento contiene una investigación que presenta resultados asociados con las actitudes de los estudiantes suramericanos hacia compañeros extranjeros, presentando datos informativos en relación a xenofobia e inmigración. La población estuvo compuesta por estudiantes activos de educación secundaria de seis ciudades representativas de países suramericanos: Buenos Aires (Argentina); São Paulo (Brasil); Santiago de Chile; Bogotá (Colombia); Guayaquil (Ecuador); y Lima (Perú). La muestra es de 1.440 estudiantes ( 240 por país) con edades comprendidas entre los 12 y 17 años de edad. Se aplicó de manera asincrónica un instrumento llamado "Test de Percepción Sociocultural" contentivo de 20 ítems presentados en una escala Likert agrupados en ítems de valoración positiva y valoración negativa. Los datos se procesaron con el Paquete Estadístico para las Ciencias Sociales (SPSS). Los resultados demuestran que en la mayoría de los países suramericanos existen entre la población escolar joven actitudes xenófobas hacia los inmigrantes suramericanos, con casos puntales en los que se observa un grado de rechazo hacia los extranjeros.

Palabras clave: estudiante extranjero, estudiante de secundaria, inmigración, xenofobia, Suramérica

Abstract: This document contains an investigation that presents results associated with the attitudes of South American students towards foreign colleagues, presenting informative data in relation to xenophobia and immigration. The population was made up of active secondary school students 
from 6 representative cities of South American countries (Buenos Aires Argentina, São Paulo Brazil, Santiago de Chile, Bogotá Colombia, Guayaquil Ecuador and Lima Peru) and a sample of 1,440 students (240 per country) with ages between 12 and 17 years old. An instrument called "Sociocultural Perception Test" was applied asynchronously, containing 20 items presented on a Likert scale grouped into positive and negative evaluation items. The data were processed with the Statistical Package for the social sciences (SPSS). The results show that in most South American countries, there are xenophobic attitudes towards South American immigrants among the young school population, with key cases in which a degree of rejection towards foreigners is observed.

Keywords: foreign student, high school student, immigration, xenophobia, South America

\section{INTRODUCCIÓN}

Las circunstancias de los distintos países suramericanos hacen que los individuos analicen constantemente sus condiciones y, en muchos casos, que evalúen la posibilidad de cambiar para mejorar sus circunstancias. Parte de ese cambio viene acompañado con la posibilidad de mudarse a otro país donde, a juicio personal, las oportunidades sean mayores y la calidad de vida sea tal que satisfaga las necesidades básicas de los individuos y de las familias. Los procesos sociales que acompañan a la globalización actualmente suponen cambios en la manera cómo se percibe a los migrantes. En pleno año 2021, los cambios tecnológicos y en la forma cómo se suceden los procesos comunicacionales vinculados a la globalización desempeñan un papel importante en el modo cómo ocurren los desplazamientos. No solo los facilitan, sino que inciden sobre la decisión de migrar, ya que permiten a los individuos mantener contacto con sus lugares de origen, además de proveer de herramientas informativas respecto a los lugares a los que se desea emigrar.

Actualmente existe una creciente y no oficializada tendencia que demuestra que una gran cantidad de profesionales deciden explorar oportunidades laborales en otros países distintos al de origen. La falta de políticas efectivas y expeditas que permitan y faciliten los procesos de legalización de estos migrantes, por lo general, tiene repercusiones negativas sobre la economía de los países receptores, ya que se desperdicia capital humano apto y preparado para desempeñarse en las distintas áreas del quehacer económico y social. Ya que en el escenario ideal los procesos migratorios futuros quedan acaparados en gran manera por jóvenes, resulta más que conveniente estudiar la manera en la que se puede educar a la población de los países receptores suramericanos que, por lo general, se caracterizan por carecer de planes, políticas y programas que encaucen y aprovechen verdaderamente a los migrantes. Con ello, se puede aprovechar de manera significativa 
los posibles aportes que estos puedan ofrecer a sus países en el contexto de una migración ordena y cada vez más dinámica y convulsa.

Los procesos migratorios actuales son multicausales, ya que pueden deberse a más de una causa. Entre las más conocidas están las causas políticas, las económicas, las de seguridad, las expectativas de mejores condiciones y calidad de vida, la reunificación familiar, el papel de las redes sociales, el rol de la familia y las ventajas laborales y socioeconómicas entre el país de origen y el país de destino.

Para Aja Díaz y otros (2017) es importante que se reconozca que, en el contexto migratorio regional y global, los migrantes actuales y los que le sucederán responden a patrones migratorios y de inserción con más similitudes que diferencias. Se refuerza la tendencia a los desplazamientos temporales, a la incorporación al mercado laboral en los sectores secundario y terciario, destacando la construcción, en el primer caso, y, en el otro, los servicios y el comercio. El movimiento se caracteriza por el flujo hacia ciudades grandes junto con ventajas comparativas con respecto a los lugares de origen. Las relaciones transnacionales se fortalecen, donde el protagonismo de las remesas marca pautas en el vínculo entre países, territorios, poblaciones y familias. La migración es, en parte, una cuestión urbana. Se vive una era de movilidad humana sin precedentes, en la que los migrantes, tanto internos como internacionales, se trasladan a las ciudades y las zonas urbanas, aportan diversidad, conectan a las comunidades dentro y fuera de las fronteras y crean nuevos vínculos entre las distintas localidades.

Es ese contexto que todos los países suramericanos deben esforzarse para que cada uno de los estudiantes activos en sus países comience a entender lo que es la migración y cuál es la realidad de los procesos asociados con este fenómeno. Es importante que, en las instituciones educativas y en todos los niveles, se promueva la enseñanza de valores como la igualdad, la equidad, la fraternidad y el respeto. Resulta prioritario que no solamente las instituciones privadas y del Estado, sino que también los individuos comprendan que la educación es uno de los principales derechos humanos. La Declaración Universal de los Derechos Humanos, en su artículo 26, contempla que la educación es una herramienta fundamental para proteger la dignidad humana. Así, es necesario que se empiece a educar de manera significativa a fin de que los estudiantes comprendan que cuando las personas están obligadas a huir para escapar a un conflicto social o económico, o, simplemente, emigran para mejorar sus condiciones de vida, la situación en su país de acogida es incierta.

Para los migrantes, la educación es la mejor herramienta para convertirse en miembros de pleno derecho de la sociedad del país receptor. Los trabajadores 
migrantes y sus hijos se benefician intelectual y socialmente de las instituciones educativas en las que se pueden adquirir conocimientos sobre la sociedad que integran. Para los migrantes indocumentados, el acceso a una educación básica aporta una cierta estabilidad, además de aumentar su autoestima. El derecho a la educación obliga a los Estados a dar acceso a ese servicio y a procurar recursos financieros para que nadie se vea privado de competencias escolares básicas, por hablar solo del mínimo indispensable.

La Convención Internacional sobre la Protección de los Derechos de Todos los Trabajadores Migratorios y de sus Familiares (1990), en su artículo 30, establece que:

[...] todos los hijos de los trabajadores migratorios gozarán del derecho fundamental de acceso a la educación en condiciones de igualdad de trato con los nacionales del Estado de que se trate. El acceso de los hijos de trabajadores migratorios a las instituciones de enseñanza preescolar o las escuelas públicas no podrá denegarse ni limitarse a causa de la situación irregular en lo que respecta a la permanencia o al empleo de cualquiera de los padres, ni del carácter irregular de la permanencia del hijo en el Estado de empleo.

Pese a que esta Convención no fue ampliamente ratificada, presenta un referente más que válido, ya que contiene obligaciones bastante claras y estrictas que velan por el cuidado y respeto de los migrantes. Además, sostiene la creación de un entorno lleno de condiciones apropiadas y verdaderamente humanas.

\section{REFERENTES TEÓRICOS}

Novaro y otros (2017) plantean que los procesos migratorios exigen un análisis del sistema educativo que aborde la realidad de la sociedad latinoamericana actual. Este, a su vez, debe cubrir las expectativas de las familias y de las organizaciones migrantes, así como la situación de las llamadas segundas generaciones. Con un estudio que permite advertir la alternancia de paradigmas de asimilación, integración e inclusión con que el sistema educativo se posiciona frente a los extranjeros, el peso del nacionalismo escolar y el modo en que los migrantes - sobre todo los latinoamericanos- fueron definidos como otros. El estudio presentó como resultado que en las escuelas primarias estudiadas existía el mantenimiento del mandato de identificación con lo nacional argentino, junto con propuestas de valorización cultural y la legitimación de nuevas presencias y voces como, por ejemplo, las fiestas escolares. En las escuelas secundarias se advirtieron fuertes contradicciones con la valorización del trabajo de los jóvenes que se registran en contextos familiares y comunitarios. Así mismo, se encentraron evidencias sobre los intentos, pero también las limitaciones, de las escuelas 
argentinas para incluir y trabajar con la condición transnacional de vida de los jóvenes migrantes y también de muchos de los hijos -e, incluso, los nietos- de los migrantes que se expresan en las festividades, en las actividades productivas y en muchos otros ámbitos formativos que también funcionan como espacios de marcación de la pertenencia.

Por su parte, García Medina (2018) -en su estudio sobre la inclusión y la convivencia para prevenir el racismo, la xenofobia y otras formas de intoleranciaexpresa que los episodios de intolerancia, odio y violencia que acontecen en todos los países del mundo impactan en las instituciones educativas. Este autor expresa que para romper el círculo que implica que la sociedad asuma la necesidad de preservar y proteger al sistema educativo se hace-necesario revitalizar espacios de convivencia protegidos. En estos cada comunidad educativa debe actuar como un verdadero refugio en el que se asuma el reto de formar ciudadanos capaces de hallar y presentar soluciones a cada uno de los problemas asociados con la convivencia escolar. Todo ello con el fin de asumir con efectividad el principio de inclusión educativa, la interculturalidad y la lucha contra cualquier forma de intolerancia, preservando la equidad de proceso educativo evitando la segregación, la discriminación y la estigmatización desde una postura humanista y crítica.

En ese sentido, Ripoll y Navas-Alemán (2018), en su investigación sobre xenofobia y discriminación hacia refugiados y migrantes venezolanos en Ecuador, expresan que la crisis política y económica en Venezuela ha transformado un país receptor de inmigrantes en un país emisor de emigrantes desde el 2010. Muchos de ellos están en situación de vulnerabilidad, siendo un $40 \%$ de dicha población niños o niñas. El cálculo por parte de la UNICEF cuantifica unos 438.000 menores venezolanos en necesidad de asistencia (UNICEF, 2018). El estudio demuestra que, pese a la movilidad y la acogida de estos refugiados y migrantes por parte Ecuador, ha habido múltiples casos de xenofobia y discriminación hacia venezolanos. UNICEF Ecuador está construyendo una estrategia de comunicación y de participación pública para complementar las acciones de apoyo a migrantes para generar y estimular una opinión pública más solidaria hacia la migración y, en particular, a los niños migrantes.

Dentro del mismo tema de estudio, Murillo Pedrozo y Agudelo Suarez (2019) exponen que los países latinoamericanos vienen enfrentando un fenómeno social y demográfico importante conocido como migración sur-sur, que difiere del patrón clásico de migración sur-norte. Ello es debido a que la capacidad de respuesta social y gubernamental es menor y por las condiciones sociales y de salud similares en ambas poblaciones, tanto migrantes como autóctonos. En la 
investigación se hace una revisión de la literatura existente en diferentes contextos geográficos, identificando los vacíos conceptuales y metodológicos, haciendo una propuesta de análisis de la migración como un determinante social con impacto en las desigualdades e inequidades en salud bucal. La conclusión es que la migración y su relación con la salud bucal en el contexto latinoamericano se encuentra en una etapa de construcción científica y esto implica la necesidad de generar propuestas de investigación basadas en la realidad social que viven los directamente involucrados desde diferentes metodologías.

Por último, conviene hacer mención que Rangel (2020) ha construido un marco analítico para profundizar el estudio de las relaciones entrecruzadas entre migración y condición étnico-racial. Ahí se aprecia una clara redundancia en prácticas racistas y xenofóbicas, y como estas se encuentran relacionadas con los procesos de inclusión y exclusión social. En la investigación se discute el tema migratorio y sus relaciones con el racismo, no solo por el aumento de personas que viven en países diferentes al que nacieron sino, principalmente, porque América Latina y el Caribe son una regiones marcadas por una matriz de desigualdad social que tiene como uno de sus ejes estructurales la condición étnico-racial. Así, se concluye que la condición de migrante puede ser un factor más de vulnerabilidad, discriminación y exclusión.

Resulta provechoso repasar la definición de Ruiz García sobre lo que es migración, constructo fenomenológico debe ser entendido como "los desplazamientos de personas que tienen como intención un cambio de residencia desde un lugar de origen a otro de destino, atravesando algún límite geográfico que generalmente es una división político- administrativa" (2002, p. 13). En el mismo orden de ideas Kearney y Beserra definen a la migración como "un movimiento que atraviesa una frontera significativa que es definida y mantenida por cierto régimen político - un orden, formal o informal- de tal manera que cruzarla afecta la identidad del individuo" (2002, p. 4).

Es importante reconocer las diferencias entre migrante y emigrante. El primero es aquella persona que decide salir de su lugar de origen para trasladarse a otro, ya sea una comunidad, Estado, o país por un intervalo de tiempo considerado, por lo que todo movimiento es una emigración con respecto a la zona de origen y una inmigración con respecto a la zona de destino. Es decir, el migrante es al mismo tiempo inmigrante y emigrante. La zona de origen, también conocida como zona de salida, es el lugar natal de donde proviene el migrante, de aquí se traslada hacia la zona de destino o de entrada, la cual se convierte en su residencia temporal o permanente. 
Para la Comisión Económica para América Latina y el Caribe -CEPAL, un órgano perteneciente a la Organización de las Naciones Unidas -ONU-, reconoce que si bien los grandes movimientos de migrantes pueden acarrear costos, también tienen un impacto social, económico y cultural notoriamente positivo en los países de origen y destino. Dicho organismo puntualiza en su informe de 2019 que los beneficios de la migración para el crecimiento económico son innegables, mencionando datos de 2015, en los que la contribución de los migrantes al PIB mundial fue de aproximadamente 6,7 billones de dólares, equivalentes al 9,4\% del PIB mundial. Así mismo, se hace necesario destacar ejemplos concretos sobre el impacto positivo de la migración en los países de destino, teniendo como papel clave el desempeño de los migrantes en la reproducción demográfica y el mercado laboral. Debe entonces reconocerse la importancia de la dimensión regional de la migración internacional, así como la necesidad de intensificar la cooperación regional.

En ese sentido, los órganos internacionales pueden contribuir a la implementación del Pacto Mundial y sus procesos regionales de seguimiento y monitoreo, a través del análisis empírico de las tendencias de la migración, para comprender sus causas fundamentales, recopilar y producir datos, proporcionar metodologías para mejorar la comparabilidad y romper el silencio estadístico. Igualmente, estos entes pueden proporcionar plataformas para la revisión regional y el establecimiento de diálogos entre los gobiernos, el sector privado, la sociedad civil y otras partes interesadas. Se hace necesaria la evaluación de los requerimientos básicos para que los migrantes y las comunidades receptoras mejoren los programas educativos y aseguren la absorción del progreso tecnológico, así como vincular la implementación del Pacto Mundial a la Cooperación Sur-Sur, incluida la mejora de la portabilidad de los derechos, la seguridad social o los títulos de educación, entre otros asuntos. Es por ello que resulta indispensable que, al abordar los resultados de estudio, se reconozca efectivamente la importancia sobre la consideración efectiva de elementos asociados a esta investigación, tales como la discriminación, la xenofobia e, incluso, el etnocentrismo.

Los científicos sociales han construido un concepto sobre la discriminación en el que se le concibe como el tratamiento desigual hacia a un sujeto o grupo, todo ello como una consecuencia directa del prejuicio. Algunos autores como Wunthnow (1982) acentúan la importancia de la discriminación, llegando a afirmar que el prejuicio solo será relevante cuando desemboque, precisamente, en discriminación. En ello influyen gran cantidad de variables, de manera que, según éstas, el comportamiento discriminatorio se manifestará en mayor o menor 
grado. Entre las variables que pueden facilitar esta expresión de la discriminación es necesario destacar la existencia de las situaciones competitivas y de conflicto, y, sobre todo, de aquellas donde los grupos implicados poseen un estatus desigual. En este contexto, la discriminación aparece como la solución de la cuestión de poder.

Recientemente, en los contextos sociales latinoamericanos, se ha empezado a emplear el término xenofobia de una manera bastante común. El Comité para la Eliminación de la Discriminación Racial -CERD, por sus siglas en inglés), órgano de expertos independientes que supervisa la aplicación de la Convención Internacional sobre la Eliminación de todas las Formas de Discriminación Racial por los Estados partes, define la xenofobia como:

[...] toda distinción, exclusión, restricción o preferencia basada en motivos de raza, color, linaje $\mathrm{u}$ origen nacional o étnico que tenga por objeto o por resultado anular o menoscabar el reconocimiento, goce o ejercicio, en condiciones de igualdad, de los derechos humanos y libertades fundamentales en las esferas política, económica, social, cultural o en cualquier otra esfera de la vida pública (CERD, 2002).

Por último, hay que hacer mención sobre lo presentado por Altarejos y Moya García-Montoto (2003), quienes presentan una definición de etnocentrismo en la que se le presenta como un ensimismamiento a nivel cultural que dificultaría gravemente la apertura de una comunidad hacia otras personas por el mero hecho de pertenecer a una cultura diferente. Entonces, al hablar de migración, ello puede traducirse como una actitud, más o menos manifiesta, respaldada o no por tesis de tipo filosófico o teórico, de menosprecio hacia otras culturas o, dicho de otro modo, una actitud en virtud de la cual una persona o comunidad estima su propia cultura como superior a las demás.

\section{MetodologíA}

\subsection{Tipo y diseño de investigación}

La presente investigación es de tipo no experimental, que según Hernández y otros (2014) es la que se ejecuta sin manipular deliberadamente variables. En este tipo de investigación no se hace variar de manera intencional las variables independientes. Lo que sí se hace es observar los fenómenos tal y como suceden en su contexto natural, para posteriormente analizarlos. Kerlinger y Lee (2002) aclaran que la investigación no experimental $\multimap$ también conocida como expo-facto- "es cualquier investigación en la que resulta imposible manipular variables o asignar aleatoriamente a los sujetos o a las condiciones" (p. 22). Tan es así que no se consideran las condiciones o estímulos a los que se expongan los 
sujetos del estudio. Dichos sujetos son valorados en su ambiente natural, en su realidad. Debe tenerse claro que en un estudio no experimental no se construye ninguna situación sino que se consideran situaciones que previamente existen que no son provocadas de modo intencional por el investigador. Así, las variables independientes ya han sucedido y no pueden ser manipuladas. El investigador no tiene control directo sobre dichas variables y tiene presente que ya ocurrieron, al igual que sus efectos.

En cuanto al diseño de esta investigación se afirma que es descriptivocorrelacional, por cuanto como lo señalan Hernández y otros (2014), este tipo de diseño propone la búsqueda específica de propiedades, características y perfiles importantes de personas, grupos, comunidades o cualquier otro fenómeno que se someta a un análisis. Mientras que lo correlacional tiene que ver con la existencia y evaluación de dos o más conceptos, categorías o variables en un contexto particular y la relación entre estas. Este tipo de estudios miden el grado de relación entre las variables y cuantifican sus relaciones.

\subsection{Población y muestra}

Para Hernández y otros (2014), la población es "el conjunto de todos los casos que concuerdan con determinadas especificaciones" (p. 174). Mientras que para Arias (2012) es "un conjunto finito o infinito de elementos con características comunes para las cuales serán extensivas las conclusiones de la investigación" (p. 81). Por su parte, Palella y Martins (2008), expresan que la población es "un conjunto de unidades de las que desea obtener información sobre las que se va a generar conclusiones" (p. 83). Al examinar estas definiciones se observa que todos los autores están de acuerdo en que la población es la totalidad del fenómeno a estudiar, donde las unidades de esta poseen una característica común que se estudia y da origen a los datos de la investigación.

En cuanto a la muestra, Tamayo y Tamayo (2006) la define como "el conjunto de operaciones que se realizan para estudiar la distribución de determinados caracteres en totalidad de una población universo, o colectivo partiendo de la observación de una fracción de la población considerada" (p. 176). En el caso de Palella y Martins (2008), definen la muestra como "una parte o el subconjunto de la población dentro de la cual deben poseer características reproducen de la manera más exacta posible" (p. 93). La muestra, según Balestrini (2008), se define como "una parte o subconjunto de la población" (p. 130). 
En la presente investigación la población estuvo compuesta por estudiantes activos de educación secundaria de seis ciudades representativas de países suramericanos -Tabla 1-, mientras que la muestra fue de 1.200 estudiantes -200 por país-con edades comprendidas entre los 12 y 17 años de edad.

TABLA 1. DisTRIBUCIÓN DE LA MUESTRA

\begin{tabular}{|c|c|c|c|c|}
\hline País & $\begin{array}{c}\text { Ciudad } \\
\text { Representativa }\end{array}$ & $\begin{array}{c}\text { Total de } \\
\text { Participantes }\end{array}$ & $\begin{array}{c}\text { Participantes } \\
\text { de género } \\
\text { femenino }\end{array}$ & $\begin{array}{l}\text { Participantes } \\
\text { de género } \\
\text { masculino }\end{array}$ \\
\hline $\begin{array}{l}\text { República } \\
\text { Argentina }\end{array}$ & Buenos Aires & 240 & 120 & 120 \\
\hline $\begin{array}{l}\text { República } \\
\text { Federativa } \\
\text { de Brasil }\end{array}$ & São Paulo & 240 & 120 & 120 \\
\hline $\begin{array}{l}\text { República } \\
\text { de Chile }\end{array}$ & $\begin{array}{l}\text { Santiago de } \\
\text { Chile }\end{array}$ & 240 & 120 & 120 \\
\hline $\begin{array}{l}\text { República } \\
\text { de Colombia }\end{array}$ & Bogotá & 240 & 120 & 120 \\
\hline $\begin{array}{l}\text { República } \\
\text { del Ecuador }\end{array}$ & Guayaquil & 240 & 120 & 120 \\
\hline $\begin{array}{l}\text { República } \\
\text { del Perú }\end{array}$ & Lima & 240 & 120 & 120 \\
\hline
\end{tabular}

Fuente: Datos obtenidos a partir del recuento final de participantes pertenecientes a la muestra.

\subsection{Instrumento, recopilación y procesamiento de los datos}

Para obtener la información se aplicó como instrumento de recopilación de información o cuestionario llamado "Test de Percepción Sociocultural" contentivo de 20 ítems. Este es una versión del test propuesto por Etxeberria Balerdi y otros (2013), con cada proposición presentada en una escala Likert agrupados en ítems de valoración positiva y valoración negativa. Todo ello con el propósito de obtener la reacción del participante a través de la selección de una de las categorías de la escala, a la cual se le asignó luego un valor numérico que va desde el 1 hasta el 10. El análisis de confiabilidad realizado para las dos escalas de los instrumentos - positiva y negativa- ofreció un índice en el Alpha de Cronbach de 0,8 para la escala positiva y de 0,795 para la escala negativa, considerando que los valores a partir de un índice de 0,7 son suficientemente fiables, se puede asegurar que, igualmente, el instrumento es certero.

$\mathrm{Al}$ obtener los datos, se procedió a procesarlos con el "Paquete Estadístico para las Ciencias Sociales"-SPSS-, que emplea procesos matemáticos de la 
estadística descriptiva, organizándolos a través de tablas de frecuencia, lo cual permitió presentar los resultados de una manera más organizada en gráficos; con ello se dio respuesta a los objetivos de la investigación.

\section{ANÁLISIS E INTERPRETACIÓN DE LOS RESULTADOS}

Una vez identificados todos los participantes, se procedió con la aplicación del instrumento, para conocer la percepción de los sujetos en relación a variables específicas: xenofobia, percepción social e inmigración en relación a individuos extranjeros en su país de origen. Se les pidió que valorasen los ítems contendidos en el instrumento - 10 positivos y 10 negativos- y que al seleccionar la valoración que ellos concediesen a cada preposición de acuerdo a una escala Likert que va de 1 a 10 puntos. El total de los ítems positivos suma 100 puntos y el de los ítems negativos igualmente suma 100 puntos.

Se presentan entonces los valores obtenidos - con un máximo 10-, organizándolos de mayor a menor, en las dos escalas que se han considerado, a fin de determinar las actitudes de los estudiantes relacionados con la inmigración. En las Tablas 2 y 3 se presentan los resultados obtenidos sobre la media de las puntuaciones positivas y la media de las puntuaciones negativas. Los resultados obtenidos en el conjunto de la muestra analizada presentan una media total de la puntaciones positivas de 7,30 sobre 10, bastante distante y por encima de los datos de la media total de las puntuaciones negativas de 3,84. Lo que evidencia que en la población escolar, de manera general, existe una percepción favorable en pro de la sana convivencia y la aceptación de otros estudiantes extranjeros.

Este balance positivo permite establecer un referente en cuanto a la defensa y cuidado de los derechos humanos los inmigrantes suramericanos y, en especial, al derecho de una educación libre de interferencias que impidan el desarrollo integral de los niños y adolescentes. Así mismo, permite tener una visión específica sobre la percepción que se tiene por país sobre los inmigrantes, en el que las opiniones parecen polarizadas teniendo datos bastante marcados, lo que a su vez da a conocer la forma en la que los estudiantes nacionales perciben a los estudiantes extranjeros. Todo ello se expone pormenorizadamente en las Tablas 2 y 3 y en las Figuras 1 y 2. 
TABLA 2. INFORMACIÓN OBTENIDA AL ANALIZAR LOS DATOS DE LA ESCALA POSITIVA EN EL INSTRUMENTO

\begin{tabular}{|c|c|c|c|c|c|c|}
\hline Ítem & $\begin{array}{l}\text { Puntua- } \\
\text { ción } \\
\text { Buenos } \\
\text { Aires, } \\
\text { Argentina }\end{array}$ & $\begin{array}{l}\text { Puntua- } \\
\text { ción } \\
\text { São } \\
\text { Paulo, } \\
\text { Brasil }\end{array}$ & $\begin{array}{l}\text { Puntua- } \\
\text { ción } \\
\text { Santiago } \\
\text { de Chile, } \\
\text { Chile }\end{array}$ & $\begin{array}{l}\text { Puntua- } \\
\text { ción } \\
\text { Bogotá, } \\
\text { Colombia }\end{array}$ & $\begin{array}{l}\text { Puntua- } \\
\text { ción } \\
\text { Guaya- } \\
\text { quil, } \\
\text { Ecuador }\end{array}$ & $\begin{array}{l}\text { Puntua- } \\
\text { ción } \\
\text { Lima, } \\
\text { Perú }\end{array}$ \\
\hline $\begin{array}{l}\text { Los extranjeros } \\
\text { deben tener los } \\
\text { mismos derechos } \\
\text { que los ciudadanos } \\
\text { de mi país }\end{array}$ & 7,11 & 8,23 & 6,99 & 6,01 & 6,32 & 4,05 \\
\hline $\begin{array}{l}\text { Gracias a los } \\
\text { ciudadanos } \\
\text { extranjeros } \\
\text { conocemos otras } \\
\text { culturas y dialectos }\end{array}$ & 8,10 & 8,89 & 8,07 & 7,62 & 7,91 & 6,84 \\
\hline $\begin{array}{l}\text { Los extranjeros } \\
\text { hacen los trabajos } \\
\text { que los ciudadanos } \\
\text { de mi país no } \\
\text { quieren hacer }\end{array}$ & 8,46 & 8,75 & 8,55 & 8,22 & 6,11 & 7,17 \\
\hline $\begin{array}{l}\text { Las personas } \\
\text { extranjeras son } \\
\text { trabajadoras }\end{array}$ & 8,11 & 9,02 & 8,54 & 7,99 & 8,58 & 7,62 \\
\hline $\begin{array}{l}\text { Las personas } \\
\text { inmigrantes son } \\
\text { gente buena }\end{array}$ & 8,88 & 9,18 & 8,17 & 7,86 & 8,25 & 5,85 \\
\hline $\begin{array}{l}\text { Las personas } \\
\text { inmigrantes hacen } \\
\text { las cosas bien }\end{array}$ & 7,52 & 9,13 & 7,99 & 6,87 & 6,87 & 6,11 \\
\hline $\begin{array}{l}\text { Con los extranjeros } \\
\text { aprendemos muchas } \\
\text { cosas }\end{array}$ & 7,11 & 8,54 & 7,64 & 7,10 & 7,22 & 5,71 \\
\hline $\begin{array}{l}\text { Las personas } \\
\text { extranjeras son } \\
\text { amables }\end{array}$ & 8,63 & 8,37 & 8,02 & 6,16 & 5,33 & 4,13 \\
\hline $\begin{array}{l}\text { Los inmigrantes nos } \\
\text { ayudan a vivir mejor } \\
\text { en este país }\end{array}$ & 7,39 & 7,73 & 7,19 & 6,43 & 5,77 & 3,95 \\
\hline $\begin{array}{l}\text { Los inmigrantes } \\
\text { ayudan a mejorar la } \\
\text { economía de mi país }\end{array}$ & 7,29 & 7,18 & 6,99 & 7,09 & 6,46 & 2,96 \\
\hline $\begin{array}{l}\text { Media puntuaciones } \\
\text { positivas }\end{array}$ & 7,86 & 8,50 & 7,82 & 7,14 & 6,88 & 5,59 \\
\hline
\end{tabular}

Fuente: Datos obtenidos al aplicar el instrumento "Test de Percepción Sociocultural" (Versionado del test propuesto por Etxeberria Balerdi y otros, 2013). 
TABLA 3. INFORMACIÓN OBTENIDA AL ANALIZAR LOS DATOS DE LA ESCALA NEGATIVA EN EL INSTRUMENTO

\begin{tabular}{|c|c|c|c|c|c|c|}
\hline Ítem & $\begin{array}{l}\text { Puntua- } \\
\text { ción } \\
\text { Buenos } \\
\text { Aires } \\
\text { Argentina }\end{array}$ & $\begin{array}{l}\text { Puntua- } \\
\text { ción } \\
\text { São } \\
\text { Paulo, } \\
\text { Brasil }\end{array}$ & $\begin{array}{l}\text { Puntua- } \\
\text { ción } \\
\text { Santiago } \\
\text { de Chile, } \\
\text { Chile }\end{array}$ & $\begin{array}{l}\text { Puntua- } \\
\text { ción } \\
\text { Bogotá, } \\
\text { Colombia }\end{array}$ & $\begin{array}{l}\text { Puntua- } \\
\text { ción } \\
\text { Guaya- } \\
\text { quil, } \\
\text { Ecuador }\end{array}$ & $\begin{array}{l}\text { Puntua- } \\
\text { ción } \\
\text { Lima, } \\
\text { Perú }\end{array}$ \\
\hline $\begin{array}{l}\text { Los extranjeros } \\
\text { reciben más ayudas } \\
\text { que los de mi propio } \\
\text { país }\end{array}$ & 2,79 & 2,48 & 2,01 & 3,45 & 4,09 & 5,33 \\
\hline $\begin{array}{l}\text { Los extranjeros } \\
\text { quitan el trabajo } \\
\text { a los de ciudadanos } \\
\text { de mi país }\end{array}$ & 1,66 & 1,24 & 2,09 & 4,28 & 5,17 & 7,61 \\
\hline $\begin{array}{l}\text { Los extranjeros son } \\
\text { más irrespetuosos } \\
\text { que las personas de } \\
\text { mi país }\end{array}$ & 1,21 & 1,01 & 1,55 & 3,87 & 5,74 & 7,96 \\
\hline $\begin{array}{l}\text { Los extranjeros nos } \\
\text { están invadiendo }\end{array}$ & 1,54 & 1,34 & 2,85 & 5,90 & 6,74 & 8,82 \\
\hline $\begin{array}{l}\text { Mi país se está } \\
\text { volviendo peligroso } \\
\text { por culpa de los } \\
\text { extranjeros }\end{array}$ & 1,18 & 1,07 & 3,54 & 4,03 & 5,11 & 8,77 \\
\hline $\begin{array}{l}\text { Los extranjeros } \\
\text { aumentan } \\
\text { la delincuencia }\end{array}$ & 2,13 & 1,22 & 4,02 & 5,46 & 7,61 & 8,66 \\
\hline $\begin{array}{l}\text { Los inmigrantes } \\
\text { tienen menos } \\
\text { formación y cultura } \\
\text { que los ciudadanos } \\
\text { de mi país }\end{array}$ & 3,82 & 1,03 & 4,28 & 5,45 & 6,10 & 4,02 \\
\hline $\begin{array}{l}\text { Los extranjeros } \\
\text { bajan el nivel } \\
\text { educativo de } \\
\text { nuestros colegios }\end{array}$ & 1,07 & 1,01 & 2,30 & 5,29 & 3,44 & 6,89 \\
\hline $\begin{array}{l}\text { Los extranjeros } \\
\text { traen enfermedades a } \\
\text { mi país }\end{array}$ & 2,10 & 1,22 & 2,62 & 3,60 & 3,71 & 5,14 \\
\hline $\begin{array}{l}\text { Los inmigrantes } \\
\text { quieren imponernos } \\
\text { sus costumbres }\end{array}$ & 3,05 & 1,03 & 1,96 & 4,86 & 4,83 & 7,16 \\
\hline $\begin{array}{l}\text { Media puntuaciones } \\
\text { negativas }\end{array}$ & 2,15 & 1,27 & 2,72 & 4,62 & 5,25 & 7,04 \\
\hline
\end{tabular}

Fuente: Datos obtenidos al aplicar el instrumento "Test de Percepción Sociocultural" (Versionado del test propuesto por Etxeberria Balerdi y otros, 2013). 
FiguRa 1. MEDia DE LAS PUNTUACIONES ObTENIDAS AL ANALIZAR LOS DATOS DE LA ESCALA POSITIVA EN EL INSTRUMENTO

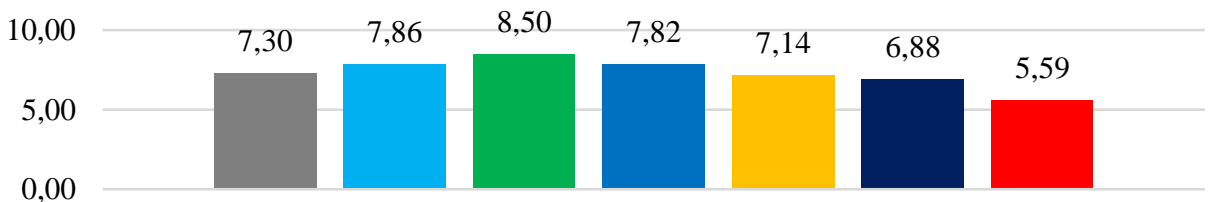

Media de puntuación positiva

- Media del total de las puntuaciones positivas

- Buenos Aires, Argentina

- São Paulo, Brasil

- Santiago de Chile, Chile

- Bogotá, Colombia

- Guayaquil, Ecuador

Fuente: Datos obtenidos al aplicar el instrumento "Test de Percepción Sociocultural" (Versionado del test propuesto por Etxeberria Balerdi y otros, 2013).

FiguRa 2. MEDIA DE LAS PUNTUACIONES OBTENIDAS AL ANALIZAR LOS DATOS DE LA ESCALA NEGATIVA EN EL INSTRUMENTO

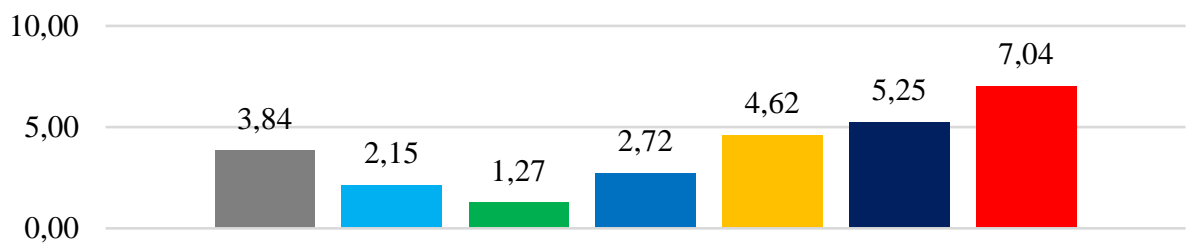

Media de puntuación negativa

- Media del total de las puntuaciones negativas

- Buenos Aires, Argentina

- São Paulo, Brasil

- Santiago de Chile, Chile

$\square$ Bogotá, Colombia

- Guayaquil, Ecuador

- Lima, Perú

Fuente: Datos obtenidos al aplicar el instrumento "Test de Percepción Sociocultural" (Versionado del test propuesto por Etxeberria Balerdi y otros, 2013). 
$\mathrm{Al}$ analizar las actitudes positivas y negativas entre los estudiantes participantes se pueden obtener datos específicos sobre conductas y actitudes. Conviene, entonces, que analicemos las elecciones de los participantes en función no solo de su escogencia sino de su nacionalidad.

\subsection{Alta receptividad hacia los inmigrantes}

$\mathrm{Al}$ analizarse las medias de los puntajes generales y por cada proposición se tiene que en el caso de la escala positiva los valores rebasan la media del total de las puntuaciones, lo que se traduce en que los participantes de estos países demuestran una actitud positiva hacia el inmigrante. Mientras que en el caso de la escala negativa para el mismo grupo de países, los valores de la media individual del país se encuentran por debajo de los puntajes total para la escala negativa, ratificando que estos países tienen un percepción favorable hacia el inmigrante.

\subsubsection{El caso brasilero: São Paulo}

Brasil se presenta como el país más amigable hacia los inmigrantes con una media en la escala positiva de 8,5. Es el valor mayor alcanzado, y se encuentra sobre los demás países considerados así como la media del total general. Las proposiciones con mayor valor reflejan la percepción general que tienen los brasileros de los inmigrantes. Con una media de 9,8 , es un valor baste elevado en la escala que expresa que "las personas inmigrantes son gente buena" y con una media de 9,13 se declara que "las personas inmigrantes hacen las cosas bien".

$\mathrm{Al}$ revisar la escala negativa presenta el valor más bajo de todo el grupo de países participantes, con una media general de 1,27 puntos, ligeramente por encima del valor mínimo permitido por elección. Ello significa casi una ausencia en la valoración negativa de los inmigrantes. El ítem con mayor índice es el que declara que "los extranjeros reciben más ayuda que los de mi propio país" con una media de 2,48, lo que necesariamente no representa algo negativo, ya que sigue siendo un valor bastante bajo. Todas las proposiciones restantes tuvieron una media ligeramente por encima del valor mínimo posible de elección; es decir de 1. Estos resultados nos permiten asegurar que Brasil es un país amigable y receptivo con los extranjeros. Los percibe como personas buenas, trabajadoras y que hacen las cosas bien. 


\subsubsection{El caso argentino: Buenos Aires}

A efectos del siguiente estudio, Argentina es el segundo país en orden de aceptación de estudiantes inmigrantes residentes en ese país. La media en la escala positiva fue de 7,86 puntos, dato que se encuentra por encima de la media del total de las puntuaciones de la escala positiva. Así, el enunciado "las personas inmigrantes son gente buena", con una media de 8,88 puntos, y el postulado "las personas extranjeras son amables", con una media de 8,63 puntos, dejan entrever la percepción positiva que se tiene de los inmigrantes entre los estudiantes participantes de la nación argentina.

En la escala negativa, Argentina sigue siendo el segundo país con el menor grado de escogencia sobre la media general de puntuaciones negativas, con 2,15 puntos de promedio. La preposición con mayor índice fue "los inmigrantes tienen menos formación y cultura que los ciudadanos de mi país" con 3,82 puntos y "los inmigrantes quieren imponernos sus costumbres". En ambos casos se evidencia un puntaje muy por debajo de la media general para la escala negativa. Estos puntajes dejan ver que el estudiante argentino valora a los inmigrantes como individuos cuyos acervos y formación académica es baja, así como un recelo en la introducción impositiva de costumbres. Estos datos nos facultan para declarar que Argentina es un país en el que los estudiantes perciben a los inmigrantes como personas buenas y amables, teniendo de su parte una actitud positiva hacía el inmigrante.

\subsubsection{El caso chileno: Santiago de Chile}

El tercer país con mayor grado de aceptación al analizar la escala positiva es Chile, con una media de 7,82 puntos. Con medias en los puntajes bastante similares están las preposiciones "los extranjeros hacen los trabajos que los ciudadanos de mi país no quieren hacer", con un puntaje de 8,55, y "las personas extranjeras son trabajadoras", con una media de 8,54 puntos. Llama la atención que los dos ítems con mayor índice de escogencia se reaccionan con el trabajo que desempeñan los inmigrantes, lo que quiere decir que, para los chilenos, las personas extranjeras llegan a su país a laborar sin distingo de actividad.

En la escala de valoración negativa, los estudiantes chilenos presentaron una media de 2,72 puntos, dato que se encuentra por debajo de la media general para la escala negativa. Con 4,28 puntos, los estudiantes expresaron su opinión en cuanto a que "los inmigrantes tienen menos formación y cultura que los ciudadanos de su país", seguida por una media de 4,02 puntos al opinar que "los extranjeros aumentan la delincuencia”. 


\subsection{Mediana receptividad hacia los inmigrantes}

$\mathrm{Al}$ considerarse las medias de los puntajes generales y de cada proposición en la escala positiva, los valores se encuentran por debajo de la media del total de las puntuaciones positivas, lo que deja ver que los participantes no tienen una actitud de rechazo hacia los inmigrantes. Sin embargo, sí guardan reservas en cuanto a temas específicos que se analizaran en los próximos apartados. En el caso de la escala negativa para el mismo grupo de países, los valores de la media individual del país se encuentran por encima de los valores totales para la escala negativa. Dado que estos valores no son significativamente distantes del valor promedio, se consideran como valores medianos. Estos demuestran que hay situaciones específicas que despiertan reservas, aunque su valoración no es de alto rechazo ni rechazo total hacia los extranjeros.

\subsubsection{El caso colombiano: Bogotá}

En el tema de los inmigrantes, los estudiantes colombianos presentan actitudes bastante positivas hacia los extranjeros con una media general en la escala positiva de 7,14 puntos, ligeramente por debajo del promedio general de la escala positiva para todos los países que es de 7,3. Los estudiantes colombianos perciben a los inmigrantes como "personas extranjeras que son trabajadoras", con un puntaje medio de 7,99 que así lo reafirma, seguido de una media de 7,86 puntos para la preposición que asegura que "las personas inmigrantes son gente buena". Siendo que ninguna de las medias de las proposiciones tiene un valor inferior a 6 puntos, podemos decir que la aceptación de los inmigrantes es bastante buena.

Lo que viene a establecer un contraste en la opinión antes mencionada queda evidenciado al analizar la media en las puntuaciones obtenidas al examinar la escala negativa, con 4, 62 puntos, por encima del promedio general total de las puntuaciones, con 3,84 puntos. El ítem en la escala negativa con mayor índice de escogencia señala que a los estudiantes colombianos les preocupa que "los extranjeros los están invadiendo", con una media de 5,90 puntos, luego de la creencia que "los extranjeros aumentan la delincuencia", con 5,46 puntos. Esta información nos habilita para decir que los estudiantes colombianos perciben a los extranjeros como personas buenas y trabajadoras, pero al mismo tiempo se sienten preocupados por el flujo que llega a su país, sintiéndose preocupados ya que esto pudiese aumentar la delincuencia en Colombia. 


\subsubsection{El caso ecuatoriano: Guayaquil}

Para los estudiantes ecuatorianos, los inmigrantes gozan de un nivel de aceptación bastante aceptable, con una media general de 6,88 puntos. Un guarismo muy cerca del total general de las puntuaciones de este país. Las actitudes parecen favorables y los inmigrantes parecen gozar de un buen nivel de aceptación y, con una media de 8,58 puntos, "las personas extranjeras son percibidas como trabajadoras", seguido de "las personas inmigrantes son gente buena", con una media de 8,25 puntos.

En contraparte se encuentran ciertos factores incidentes en la percepción desfavorable por parte de los estudiantes ecuatorianos participantes hacia los extranjeros. Tal es que el ítem con el mayor índice de escogencia señala que "los extranjeros aumentan la delincuencia", con una media de 7,61 puntos, seguido por la declaración que "los extranjeros nos están invadiendo", con una media de 6,74 puntos. En el caso de los estudiantes ecuatorianos se puede observar una especie de dualidad en la percepción que se tiene de los inmigrantes. No hay una polarización contundente que señale si se percibe la presencia de los extranjeros como un hecho totalmente bueno o definitivamente malo.

\subsection{Baja receptividad hacia los inmigrantes}

Una vez procesados los datos, se seleccionaron las medias de los puntajes más bajos de la escala positiva, lo que establece cuáles países tienen una actitud negativa hacia los inmigrantes. Igualmente, para la escala negativa, se procesaron los datos de aquellos cuyas medias por ítem presentaron un puntaje alto. Todo ello para definir qué tan bajo es el nivel de aceptación de los estudiantes participantes hacia los extranjeros.

\subsubsection{El caso peruano: Lima}

Para los estudiantes participantes pertenecientes a Perú, el índice de aceptación de los extranjeros se encuentra ligeramente por encima de la mitad del puntaje posible. Esto es, da una media de 5,59 contrastada con los 7,3 puntos del promedio general total de aceptación en la escala positiva. Las preposiciones con mayor escogencia son "las personas extranjeras son trabajadoras" y "los extranjeros hacen los trabajos que los ciudadanos de mi país no quieren hacer", con 7,17 puntos de media. En ambos casos, los ítems con el mayor grado de escogencia se encuentran relacionados con la disposición que tienen los extranjeros para trabajar. 
$\mathrm{Al}$ analizarse los datos referentes a la percepción que se refleja, según la información de la escala negativa, los participantes expresaron su percepción sobre los extranjeros dejando saber que, a su juicio, contribuyen a la peligrosidad del país, inclusive aumentando la delincuencia. Los estudiantes peruanos presentaron una media de 7,04 puntos de percepción negativa sobre los extranjeros, dato que casi es el doble de la media del total de la percepción negativa. En el caso de los ítems con mayor media sobre el puntaje se tuvieron "mi país se está volviendo peligroso por culpa de los extranjeros", con 8,77 puntos, y "los extranjeros aumentan la delincuencia”, con 8,66 puntos. Estos datos evidencian que los peruanos tienen una actitud de baja receptividad hacia los inmigrantes.

\subsection{Una aproximación de la relación entre el género y la receptividad hacia los inmigrantes}

Una vez procesados los datos, se procedió a agrupar a los participantes en atención a su nacionalidad y el género, entendiendo este como el género biológico y el género con el que se auto percibe, a efectos de este este estudio se les agrupa en masculino y femenino, tal y como se aprecia en las Tablas 4 y 5 y las Figuras 3 y 4.

TABLA 4. ESCALA POSITIVA SOBRE LA RELACIÓN ENTRE EL GÉNERO Y LA RECEPTIVIDAD HACIA LOS INMIGRANTES

\begin{tabular}{lc}
\hline \multicolumn{1}{c}{ Género considerado } & $\begin{array}{c}\text { Media del total de las puntuaciones } \\
\text { positivas }\end{array}$ \\
\hline Todos los participantes & 7,30 \\
Femenino & 8,05 \\
Masculino & 6,59 \\
\hline
\end{tabular}

Fuente: Datos obtenidos al aplicar el instrumento "Test de Percepción Sociocultural” (Versionado del test propuesto por Etxeberria Balerdi y otros, 2013).

TABLA 5. ESCALA NEGATIVA SOBRE LA RELACIÓN ENTRE EL GÉNERO Y LA RECEPTIVIDAD HACIA LOS INMIGRANTES

\begin{tabular}{lc}
\hline Género considerado & $\begin{array}{c}\text { Media del total de las puntuacio- } \\
\text { nes negativas }\end{array}$ \\
\hline Todos los participantes & 3,84 \\
Femenino & 1,71 \\
Masculino & 5,97 \\
\hline
\end{tabular}

Fuente: Datos obtenidos al aplicar el instrumento "Test de Percepción Sociocultural" (Versionado del test propuesto por Etxeberria Balerdi y otros, 2013). 
FIGURA 3. ESCALA POSITIVA SOBRE LA RELACIÓN ENTRE EL GÉNERO Y LA RECEPTIVIDAD HACIA LOS INMIGRANTES

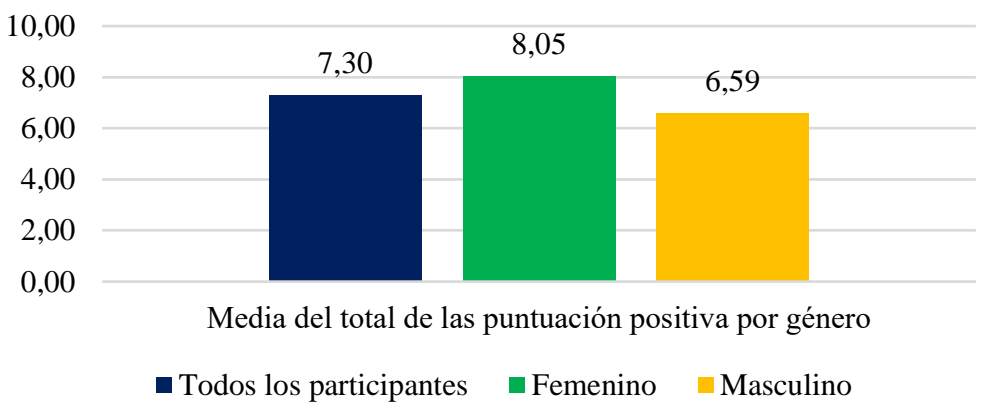

Fuente: Datos obtenidos al aplicar el instrumento "Test de Percepción Sociocultural" (Versionado del test propuesto por Etxeberria Balerdi y otros, 2013).

\section{FIGURA 4. ESCALA NEGATIVA SOBRE LA RELACIÓN ENTRE EL GÉNERO Y LA RECEPTIVIDAD HACIA LOS INMIGRANTES}

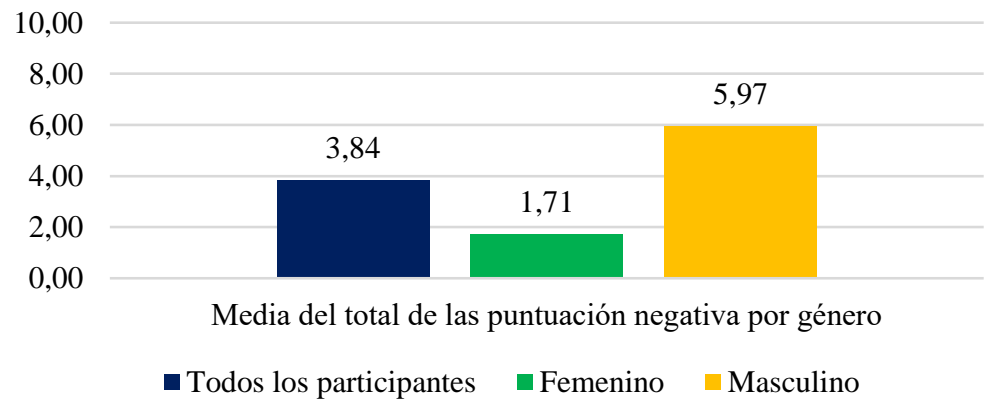

Fuente: Datos obtenidos al aplicar el instrumento "Test de Percepción Sociocultural" (Versionado del test propuesto por Etxeberria Balerdi y otros, 2013).

Para procesar y analizar los datos relativos al género y a la actitud de estos subgrupos hacia los inmigrantes, se consideraron todos los participantes, teniendo que de los 1.440 sujetos, la mitad, -es decir 720 sujetos- eran féminas y la otra mitad eran varones. Al analizar las puntuaciones obtenidas en la escala positiva y compararla con la media del total de las puntuaciones $-7,3$ puntos-, se halló que las mujeres, con un 8,05 puntos, presentan un mayor puntaje que los hombres, siendo que estos tuvieron una media de 6,59 puntos en la escala positiva.

Por su parte, al analizar las valoraciones presentadas en la escala negativa, se compararon los datos con la media del total de las puntuaciones $-3,84$ puntos-, y se encontró que las mujeres presentaron 1,71 puntos y los hombres 
5,97. Lo que demuestra dos cosas importantes: la primera es que la valoración que presentaron las mujeres es casi de la mitad del total de las puntuaciones; y la segunda es que en el caso de los hombres sucede lo opuesto, pues ellos casi duplican el valor de la media de las puntuaciones negativas. Ello refleja que en general, y a efectos de este estudio, las mujeres tienen una mejor actitud y mayor grado de aceptación hacia los inmigrantes.

\section{CONCLUSIONES}

Pese a que los procesos migratorios se vuelven un factor social, global y cotidiano, aún no existe una educación real e instrumental sobre lo que son los movimientos migratorios y el impacto que estos ejercen sobre las dinámicas sociales, económicas, afectivas y, más importante, sobre las educativas. Basta con ingresar a cualquier navegador, publicación digital o empresa para buscar una definición o concepto reciente emitida por autores, investigadores o instituciones sobre los principales conceptos asociados a la migración tales como migrante, emigrante, inmigrante, residente o refugiado.

Más allá de poner toda la atención sobre las políticas migratorias de cada país y señalar que carecen de uniformidad, es fundamental educar verdadera y significativamente a la llamada población de relevo, la cual se encuentra en proceso de formación social y académica. La falta de claridad sobre lo que es la xenofobia, el racismo y las micro-agresiones hacia nativos y, en este caso, hacia migrantes solo son una arista del problema. Debido a ello es fundamental y medular que la problemática asociada a la percepción de los migrantes entre los países suramericanos sea abordada desde los centros del saber. Es decir, desde las escuelas, los liceos y las universidades.

La migración actual entre los países suramericanos se da por la proximidad cultural, idiomática e histórica entre los países emisores y receptores. Sin embargo, las dificultades no dejan de ser visibles y acentuadas. La inserción educativa per se es compleja y, en ocasiones, hasta precaria. En muchos casos estos desplazamientos ocurren de manera forzada. Ello, junto a las políticas migratorias restrictivas, se convierten en elementos que sitúan a la población migrante en una condición de vulnerabilidad. Infelizmente, desde las instituciones educativas suramericanas no hay espacios para la sensibilización sobre esta problemática. La consecuencia es que genera una visión unilateral hacia el extranjero, con opiniones polarizadas que van desde percibir a los migrantes como personas buenas 
o malas, trabajadoras o delincuentes, juzgando a las comunidades de migrantes como un todo y en función tal vez de una única experiencia.

En Suramérica, y a partir de la información obtenida de las ciudades participantes, se puede decir que el migrante es bien recibido en la mayoría de los países. Al tratarse de naciones como Brasil, Argentina y Chile se demuestra una actitud bastante favorable hacia los extranjeros, pero con recelo de conservar su identidad y no verse impactados por costumbres o culturas ajenas. Así mismo, el caso de Brasil resulta interesante, ya que parece ser altamente receptivo a ciudadanos extranjeros, presentándose como libre de prejuicios y teniendo una percepción muy favorable de los migrantes.

En el caso de países como Colombia y Ecuador, la situación demuestra no estar completamente definida en cuanto a cómo se percibe a los migrantes. Hay una visión marcada en algunos temas como la delincuencia y la inseguridad, que a juicio de los participantes se alimenta de la llegada de los migrantes. En contraposición se percibe a los extranjeros como personas buenas por naturaleza, quienes son amigables y trabajadoras. En casi todos los países -5 de 6 - se sujeta la creencia que los extranjeros deben contar con los mismos derechos que sus connacionales. Igualmente, se piensa que los extranjeros realizan aportes culturales y hasta idiomáticos, y se les percibe como personas capaces de enseñar cosas nuevas a los ciudadanos propios. En general, son vistos como amables y agentes del cambio positivo para el país que los recibe.

Los resultados demuestran que no hay preocupación de que los extranjeros reciban más ayuda que los del propio país, ni sobre la pérdida de trabajo a manos de los extranjeros. De igual modo, no se les considera como inferiores en lo que a su formación académica y social respecta, y no se les ve como amenazas impositivas desde el punto de vista cultural. También se encontró que los estudiantes no perciben a los migrantes como elementos que disminuyan la calidad educativa de sus instituciones, ni como agentes transmisores de enfermedades. En casos como los de Perú y Ecuador, existe una preocupación manifiesta respecto a la posible invasión de los extranjeros.

El estudio presenta una información sobre el género y la forma cómo se perciben a los inmigrantes, encontrando que las mujeres tienen una percepción y actitud más favorable hacia estos que la que tienen los hombres.

En mi modesta opinión, estudios como el presente contribuyen a crear una fuente de información actualizada. Así mismo, se aportan datos concretos sobre la percepción que se tiene de los migrantes. Las limitaciones de este estudio vienen dadas por la generalidad del mismo. Resultaría conveniente que en futuras 
investigaciones se consideren unas tres ciudades representativas por país. También se sugiere hacer investigaciones relativas a cómo se perciben los migrantes por nacionalidad y grupos etarios entre los distintos países de Suramérica. De igual manera, un estudio de género y de percepción de los inmigrantes por país podría aportar datos con información relevante sobre la interrelación que hay en estos dos elementos.

\section{REFERENCIAS BIBLIOGRÁFICAS}

Aja Díaz, A., Rodríguez Soriano, M., Orosa Busutil, R., \& Albizucampos Espineira, J. (2017). La migración internacional de cubanos: Escenarios actuales. Revista Novedades en Población, 13(26), 40-57.

Altarejos M., F., \& Moya García-Montoto, A. (2003). Del relativismo cultural al etnocentrismo (y vuelta). Estudios sobre Educación, (4), 23-34.

Arias, F. (2012). El proyecto de investigación: Introducción a la metodología científica (6 ${ }^{\text {a }}$ Edición). Editorial Episteme.

Balestrini A. M. (2008). Como se elabora el proyecto de investigación. Bl Consultores Asociados.

Convención internacional sobre la protección de los derechos de todos los trabajadores migratorios y de sus familiares, 18 de diciembre de 1990, Organización de Naciones Unidas, https://www.ohchr.org/sp/professionalinterest/pages/cmw.aspx

CERD. (2002). Informe anual del CERD. Doc. ONU A/57/18, párr. 406, 445.

Etxeberria Balerdi, F., Murua Cartón, H., Garmendia Larrañaga, J., \& Etxeberria Murgiondo, J. (2013). Prejuicios, inmigración y educación: Actitudes del alumnado de secundaria en el País Vasco. Revista de Psicología y Educación, 8(1), 25-49.

García Medina, R. (2018). Inclusión y convivencia para prevenir el racismo, la xenofobia y otras formas de intolerancia: Uno de los retos principales de nuestro sistema educativo. Ciencia, Técnica y Mainstreaming Social, (2), 53-65. https://doi.org/10.4995/citecma.2018.9852

Hernández, R., Fernández, C., y Baptista, L. (2014). Metodología de la Investigación (4ª Edición). McGraw-Hill.

Kearney, M., \& Beserra, B. (2002). Migration and identities: A class-based approach. Latin American Perspectives, 31(5), 3-14.

Kerlinger, F., \& Lee, H. (2002). Investigación del comportamiento: Métodos de Investigación en Ciencias Sociales. McGraw-Hill.

Murillo Pedrozo, A. M., \& Agudelo Suárez, A. A. (2019). La migración sur/sur como un determinante social de impacto en las desigualdades e inequidades en salud bucal en Latinoamérica. Revista Peruana de Medicina Experimental y Salud Pública, 36(4), 692-699. https://doi.org/10.17843/rpmesp.2019.364.4908.

Novaro, G., Diez, M., \& Martinez, L. (2017). Educación y migración latinoamericana: Interculturalidad, derechos y nuevas formas de inclusión y exclusión escolar. Migraciones Internacionales, (2), 7-23. 
Palella, S., y Martins, F. (2008). Metodología de la investigación cuantitativa (2a Edición). FEDUPEL.

Rangel, M. (2020). Protección social y migración: El desafío de la inclusión sin racismo ni xenofobia. Serie Políticas Sociales, (232), 1-54.

Ripoll, S., \& Navas-Alemán, L. (2018). Xenofobia y Discriminación Hacia Refugiados y Migrantes Venezolanos en Ecuador y Lecciones Aprendidas para la Promoción de la Inclusión Social. IDS; UNICEF. https://opendocs.ids.ac.uk/opendocs/bitstream/handle/20.500.12413/14130/Informe_XD_e_inclusion_social_en_Ecuador_Dec_2018_es.pdf

Ruiz García, A. (2002) Migración oaxaqueña, una aproximación a la realidad. Coordinación Estatal de Atención al Migrante Oaxaqueño.

Tamayo y Tamayo, M. (2006). Técnicas de Investigación (2a Edición). Mc Graw-Hill.

UNICEF. (2018). Migration flows in Latin America and the Caribbean: Situation Report 8th October-8th November. UNICEF.

Wunthnow, R. (1982). Antisemitism and stereotyping: In the eye of the beholder. Praeger. 